\title{
DIGITAL ECONOMY, TAXATION AND PROBLEMS ENCOUNTERED
}

\author{
DOI: 10.17261/Pressacademia.2020.1234 \\ PAP- V.11-2020(6)-p.28-33
}

\section{Huseyin Mert ${ }^{1}$, Erhan Bayar²}

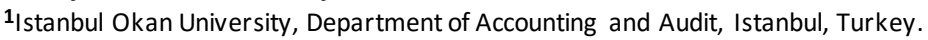
huseyin.mert@okan.edu.tr, ORCID: 0000-0001-5391-7865

2Istanbul Okan University, Department of Accounting and Audit, Istanbul, Turkey. erhan.bayar@gmail.com, ORCID: 0000-0002-1892-5429

\section{To cite this document}

Mert, H., Bayar, E. (2020). Digital economy, taxation and problems encountered. PressAcademia Procedia (PAP), V.11, p.28-33

Permanent link to this document: http://doi.org/10.17261/Pressacademia.2020.1234

Copyright: Published by PressAcademia and limited licensed re-use rights only.

\begin{abstract}
Purpose- With the developments in information and communication technology; multinational companies, which are operating in the digital field, have been able to engage in commercial activities without having any physical presence in countries where they are not resident. With digital transformation, the loss of physical assets is now a major problem in the taxation of these activities. As a result of this, base erosion and profit transfer (BEPS) are on the agenda and it is seen that countries are turning to unilateral measures because of the lack of tax revenues that can be obtained in this area. In this context, the purpose of the study is to examine the form of the digital economy and taxation issues and the evaluation of Turkey's enforcement of the measure.

Methodology- The size of digital economy, and the problems related to its taxation and studies of Turkey's practices for its taxation will be mentioned.

Findings- Considering the direction of digital services that crosses the borders of the country, unilateral measures implemented by the countries are insufficient in solving the problem of taxation of the digital economy and the tax and / or taxes to be introduced may cause other problems such as double taxation. Therefore, the need to find a fair, multilateral international solution at the OECD level has come to the fore in order to develop methods that protect the rights of countries and prevent tax planning and tax avoidance.

Conclusion- Addressing this issue at international level and ensuring the necessary consensus is important for maintaining and ensuring equality between companies.
\end{abstract}

Keywords: Digital economy, digital service tax, taxation of digital economy, avoidance of tax, tax law.

JEL Codes: H25, H26, K34

\section{DiJITAL EKONOMI, VERGILENDIRILMESI VE KARŞILAŞILAN SORUNLAR}

\section{ÖZET}

Amaç- Bilgi ve iletişim teknolojisi alanında yaşanan hızlı gelişmeler ile birlikte dijital alanda faaliyet gösteren çok uluslu şirketler, mukimi olmadıkları ülkelerde herhangi bir fiziksel varlığa sahip olmadan ticari faaliyette bulunma ve kazanç elde etme imkanına kavuşmuştur. Dijital dönüşüm ile birlikte fiziki varlığın artık önemini kaybetmesi bu faaliyetlerin vergilendirilmesinde temel sorun olarak karşımıza çıkmaktadır. Bunun sonucu olarak matrah aşındırma ve kar aktarımı gündeme gelmekte ve ülkeler in bu alanda elde edilebilecek vergi gelirlerinden mahum kalması nedeniyle tek taraflı önlemlere yönenildiği görülmektedir. Bu çerçevede çalışmanın amacını, dijital ekonomi ve vergilendirilmesi ile ilgili sorunların incelenmesi ile Türkiye' nin yürürlüğe koyduğu önlemlerin değerlendirilmesi oluşturmaktadır.

Yöntem- Dijital ekonominin ulaştığı boyut, vergilendirilmesine yönelik sorunlar ve konuyla ilgili Türkiye' nin uygulamaya koyduğu önle mlere değinilecektir.

Bulgular- Dijital hizmetlerin ülke sınırlarını aşan yönü dikkate alındığında, ülkelerin uygulamaya koyduğu tek taraflı önlemler dijita। ekonominin vergilendirmesi sorununu çözmede yetersiz kalmaktadır. Aynı zamanda bu alanda ihdas edilen/edilecek vergi ve/veya vergiler çifte vergilendirme gibi başka sorunlara neden olabilmektedir. Dolayısıyla; ülkelerin hakla rını gözeten, vergi planlaması yapmayı ve vergiden kaçınmayı önleyen yöntemlerin geliştirilmesi için OECD düzeyinde adil, çok taraflı bir uluslararası çözüm bulunması gerekliliği ön plana çıkmıştır.

Sonuç- Bu yönde atılacak adımların şirketler arasında eşitliğin korunması ve sağlanması adına uluslararası düzeyde ele alınması ve gerekli konsensüsün sağlanması önem arz etmektedir.

Anahtar Kelimeler: Dijital ekonomi, dijital hizmet vergisi, dijital ekonominin vergilendirilmesi, vergiden kaçınma, vergi hukuku JEL Kodları: F65, H25, H26, K34 


\section{GíRiş}

Dijitalleşme, sanayi devriminden sonra küresel ekonomideki en önemli gelişmelerden biri olarak değerlendirilmektedir. Aynı za manda yeni bir ekonomik model olarak da ifade edilen dijital ekonomi, gün geçtikçe daha hızlı büyümektedir. Bu süreç yalnızca geleneksel işletme biçimlerini değiştirmekle kalmamakta, aynı zamanda mevcut vergileme rejimlerini de ciddi ölçüde etkilemektedir. Bu nedenle OECD bünyesinde dijital ekonominin etkin ve adil bir şekilde vergilendirilmesine yönelik çalışmalar yapılmaktadır. Ancak bu çalışmalar henüz nihai sonuca ulaşmış değildir.

Dijital ekonominin vergilendirilmesinde ön önemli sorunun fiziksel varlığın artık önemini kaybetmesi olduğunu söyleyebiliriz. Sanal ortamda artık şirketler mukimi olmadıkları ülkelerde önemli kazançlar elde etmektedir. Verginin kamusal hizmetlerin sunumunda temel finansman kaynağı olduğu dikkate alındığında ülkelerin dijital hizmetlerin vergilendirilmesine yönelik tek taraflı önlemler almaya başladığı da görülmektedir.

Bu kapsamda, çalışmada öncelikle dijital ekonomi kavramı analiz edilmiş ve Türkiye' de Mart 2020' den itibaren yürürlüğe giren dijital hizmet vergisi incelenerek beraberinde getirdiği sorun ve sorunsallar analiz edilmeye çalışılmıştır. Daha sonra dijital ekonominin vergilendirilmesine yönelik sorunlar incelenmiştir. Son olarak yapılan bu tespitler neticesinde değerlendirmelerde bulunularak öneriler sunulmuştur.

\section{DiJTTAL EKONOMi}

“Dijital ekonomi (digital economy)” kavramının, ilk kez D. Tapscott (1994) tarafından “Dijital Ekonomi: Bilişim Ağına Dayalı Zeka Çağında Umut ve Tehlike (The Digital Economy: Promise and Peril in the Age of Networked Intelligence)" isimli yapıtında kullanıldığı belirtilmektedir (Birinci, 2019: 508). "Bilgi ekonomisi", "ağ ekonomisi" veya "yeni ekonomi" gibi terimlerle de ifade edilen (Mastar Özcan, 2016: 74) bu kavram; teknolojiyi daha ucuz, daha güçlü ve yaygın hale getiren, iş süreçlerini geliştiren ve ekonominin tüm sektörlerinde yeniliği destekleyen bilgi ve iletişim teknolojisinin getirdiği dönüşüm süreci olarak tanımlanabilir (OECD, 2015: 11).

Dijital ekonominin en önemli özelliklerinden biri; dijital ürün ve/veya teknolojilere dayanan mal ve hizmetlerin herhangi ulusal veya uluslararası bir sınırlamaya tabi olmaksızın ticarete konu olmasıdır. Böylelikle ticaret; küresel bir nitelik kazanmakta, ticarete ilişkin ödeme, üretim, pazarlama gibi konularda köklü değişiklikler yaşanmaktadır (Yıldız ve Günay, 2018: 4005). OECD tarafından yayımlanan Final/Sonuç Raporu'nda dijital ekonomiyi karakterize eden temel özellikler; azalan giriş engelleri ve hızla gelişen teknolojinin neden olduğu değişkenlik, kullanıı katıımı, verilere güven, hareketlilik, pazarın iki tarafının da farklıvergilendirme bölgelerinde olabileceği çok tarafı iş modellerinin kullanılması, büyük ölçüde ağ etkilerine dayanan belirli iş modellerinde tekel veya oligopole eğilim, entegrasyon ve sinerji ile anlaşılan ağ etkileri olarak belirtilmiştir (OECD, 2015: 64-65).

Dijitalleşmenin ekonomi alanında yarattığı dönüşümler kapsamında, dijital ekonominin sahip olduğu diğer genel özellikleri de aşağıdaki gibi sıralamak mümkündür (Akyazı ve Kalça, 2003: 224; Aslan, 2009: 304):

- $\quad$ Fiziki nitelikteki mal ve hizmetlerin dünya ekonomisindeki payı azalmaktadır. Dijital ekonomin önemli özelliklerinden biri; ürünlerin giderek bilgiye dayalı ve hizmet temelli hale gelmesidir. Dolayısıyla dijital nitelikteki mal ve hizmetlerin dünya ekonomisindeki ağırlığı giderek daha da artmaktadır.

- Ekonominin dijitalleşmesiyle verimlilik artmaktadır. Özellikle yüksek ekonomik verimlilik sağlayan buluşların olması, ekonomik sektörlerin tamamında verimliliğin artmasına neden olmuştur.

- Müşteri ve üretici yakınlaşması artmıştır. Hem üreticiler hem de müşteriler hizmet kalitesinin ve ürün çeşitliliğinin artmasının yanı sıra, fiziki engeller yaşamadan dünyanın her yerinden pazar ve ürün hakkında detaylı bilgi sahibi olma imkanı yakalamaktadır.

- Dijital ekonomi, daha piyasa odaklı, yenilikçi, rekabetçi ve küresel niteliktedir. Piyasaların küresel nitelik kazanmasıyla müşterilerin talepleri çeşitlenmekte ve artmaktadır. Böylelikle işletmelerin daha küresel düzeyde düşünmek zorunda kalarak, yenilik ve kaliteye verdikleri önemi arttırmaları beklenmektedir. Aynı zamanda sayılan bu özellikler dijital ekonomiyi klasik ekonomiye göre daha az istikrarlı yapmaktadır.

- Bilgiye ve kalifiye elemana olan ihtiyaç artmıştır. Dijitalleşmeyle beraber pek çok yeni iş sahası doğmuştur. Klasik üretim faktörleri ortadan kalkmamakla beraber, dijitalleşmeyle beraber bilginin daha ön plana çıktığı, dolayısıyla iyi eğitimli ve kalifiye çalışanlara intiyacın belirginleştiği söylenebilir.

- Dijital ekonomi, küresel bölünmeyi arttırmaktadır. Dijital ekonominin ortaya çıkaracağı problemlerden biri de; gelişmiş ve gelişmekte olan ekonomiler arasındaki gelir ve teknoloji farkını arttırmasıdır. Zira; sosyo-ekonomik gelişimini yeteri kadar tamamlayamamış gelişmekte olan ülkelerin, dijitalleşme sürecini yakından takip etmeleri gelişmiş ülkelere nazaran oldukça zordur.

Dijital ekonomi aynı zamanda yeni bir ekonomik modeli de ifade etmektedir (Oktay, 2020: 97). Dijital ekonominin oluşturduğu iş modelleri olarak, e-ticaret, online reklamcllı, bulut depolama ve online ödeme hizmetleri, sanal uygulama marketleri, sosyal medya platformları gibi uygulamalar söylenebilir (European Parliament, 2016: 15). Bunlar dışında blockchain, paylaşım ekonomisi iş modelleri, nesnelerin interneti, gelişmiş robotik sistemler, 3-D yazıcı iş modelleri, yapay zeka gibi iş modelleri de hızlı bir gelişme göstermektedir (Oktay, 2020: 97). Bu iş modelleri içerisinde ise "fiziki olarak karşı karşıya gelmeksizin, elektronik ortamda gerçekleştirilen çevrim içi iktisadi ve ticari her türlü faaliyeti" (6563 Sayılı Kanun) içeren e-ticaretin en yaygın kullanılan iş modeli olduğunu söyleyebiliriz (Oktay, 2020: 97).

Dijital ürün ve teknolojilere dayanan mal ve hizmetlerin hacminin büyümesi ve çeşitlenmesiyle birlikte, yukarıda belirtilen yeni iş model ve fikirlerinin ortaya çıkması sağlanmış olsa da; ulusal vergi sistemleri söz edilen gelişmelere ayak uydurmakta zorlanmış ve ye tersiz kalmıştır (Yıldız ve Günay, 2018: 4006). Buradaki önemli problem, fiziki varlığın dijital ekonomide önemini kaybetmesi, dijitalleşmenin sebep olduğu yeni iş modellerinin şirketlerin belirli bir ülkede herhangibir fiziki bir varlığa sahip olmadan büyük kazançlar elde etmesine olanak sağlamasıdır 
(Birinci, 2019: 510). Diğer zorluklar ise, dijital iş modellerinin çeşitliliği ve mükelleflerin gerçek kimliğinin belirlenmesidir (Birinci, 2019: 510). Bu zorlukların doğal bir sonucu olarak dijital ekonomiden sağlanan kazançların kayıt altına alınabilmesi için yeniden düzenle nmiş bir vergi sistemi gerekmektedir (Yüce ve Akbulut, 2018: 111). Eğer vergi sisteminde gerekli düzenlemeler yapılmaz ise, ulusal ekonomiler zarar görebilecek ve haksız rekabet koşulları daha fazla artacaktır (Boccia, 2016: 3). Bu sebeple OECD başta olmak üzere, Avrupa Birliği ve diğer ülkeler kendi haklarını gözeten ve vergi planlaması yapmayı ve vergiden kaçınmayı önleyen daha adil vergilendirme yol ve yöntemleri tartışmaya ve geliştirmeye başlamışlardır (Oktay, 2020: 98).

\section{TÜRKIYE'DE DiJITALEKONOMININ VERGILENDIRILMESINE YÖNELiK DÜZENLEMELER}

\subsection{Dijital Hizmet Vergisi}

7194 sayılı Kanun'da yer alan ve 1 Mart 2020 tarihinde yürürlüğe giren dijital hizmet vergisinin konusunu; dijital ortamda sunulan her türlü reklam hizmetleri (reklam kontrol ve performans ölçüm hizmetleri, kullanıcılarla ilgili veri iletimi ve yönetimi gibi hizmetler ile reklamın sunulmasına ilişkin teknik hizmetler dahil), sesli, görsel veya dijital herhangi bir içeriğin (bilgisayar programları, uygula malar, müzik, video, oyunlar, oyun içi uygulamalar ve benzerleri dahil) dijital ortamda satışı ile bu içeriklerin dijital ortamda dinlenmesine, izlenmesine, oynanmasına veya elektronik cihazlara kaydedilmesine veya bu cihazlarda kullanılmasına yönelik dijital ortamda sunulan hizmetler, kullanıcıların birbirleriyle etkileşime geçebilecekleri dijital ortamların sağlanması ve işletilmesi hizmetleri (kullanıcılar arasında bir mal veya hizmetin satılmasına veya satılmasının kolaylaştırılmasına yönelik sunulan hizmetler dahil) ve söz konusu hizmetlere yönelik dijital ortamda dijital hizmet sağlayıcıları tarafından verilen aracılık hizmetleri oluşturmaktadır.

Dijital hizmet vergisinin mükellefi, dijital hizmet sağlayıcılarıdır. İlgili hesap döneminden önceki hesap döneminde, Türkiye'den elde edilen hasılatı 20 milyon TL'den veya dünya genelinde elde edilen hasılatı 750 milyon avrodan veya muadili yabancı para karşıllı̆ı TL'den az olanlar vergiden muaf tutulmaktadır

Dijital hizmet vergisinin matrahı, ilgili vergilendirme döneminde verginin konusuna giren hizmetler nedeniyle elde edilen hasılattır. Hasılatın döviz ile hesaplanması halinde döviz, hasılatın elde edildiği tarihte geçerli olan Merkez Bankası döviz alış kuru üzerinden Türk parasına çevrilir. Kanunda dijital hizmet vergisinin oranı ise \%7,5 olarak belirlenmiştir. Dijital hizmet vergisinde ver gilendirme dönemi takvim yılının birer aylk dönemleri olarak belirlenmiş ancak Hazine ve Maliye Bakanlı̆ı’'na üçer aylık vergilendirme dönemi tespit etme konusunda da yetki verilmiştir. Mükellefler ve vergi kesintisi yapmakla sorumlu olanlar, kanunun 6. ma ddesinin 3. fıkrasına göre; beyannamelerini takip eden ayın sonuna kadar vergi dairesine vermeye ve 6 . fıkraya göre aynı süre içinde ödemekle yükümlüdürler.

Dijital hizmet vergisinin yürürlüğe girmesi birçok tartışmayı beraberinde getirmiştir. Aşağıda bu kapsamda literatürde yapılan tartışmalar özetlenmeye çalışılmıştır.

- Dijital hizmet vergisikapsamındaki “her türlü”, "gibi” ve "ve benzerleri” kelimeleri (edatları) kullanımasının dijital hizm et vergisinin konusunu belirsiz bıraktığı ve böylece vergi idaresinin bu konuyu oldukça geniş yorumlayabileceği ile bir çok durumu bu konu kapsamına alabileceği intimalinin olduğu ve dolayısıyla bu durumun bir çok uyuşmazlığı beraberinde getirebileceği düşünülmektedir (Ülkü, 2020: 121).

- Dijital hizmet vergisinin dijital ortamda faaliyette bulunan işletmelerin hasılat düzeylerine yönelik eşik çizildiği için bu ortamda faaliyet gösteren bütün işletmelerin bu verginin kapsamına girmeyeceği fakat ilgili hesap dönemi içerisinde bu eşiklerin her ikisinin de aşılması durumunda dijital hizmet vergisine ilişkin muafiyetin sona ereceği ve buradaki ilgili hesap döneminin belirsizlik taşıdığı ve muafiyet durumu belirlenirken hem hesap dönemi hem vergilendirme dönemi kavramlarının birlikte kullanılmasının da belirsizlik yarattığı ve bu bağlamda, bu kavramların tanımlar kısmında açık ve net bir şekilde belirtilmesinin gerektiği değerlendirilmektedir (Ülkü, 2020: 121).

- Bu verginin daha çok vergi sorumluları aracılığı ile tahsil edileceği düşünüldüğünde, verginin bu yönüyle de mali güce göre vergilendirme ilkesini ihlal edeceği ortadadır. Zira aynı mali güce sahip iki kişiden biri muafiyet sınırının üstünde kalan bir işletmeden örneğin dijital ortamda sunulan bir reklam hizmetini aldığında vergi ödemek zorunda kalacak iken, muafiyet sınır ının altında kalan bir işletmeden bu hizmeti aldığında vergi ödemeyecektir. Ödenecek olan dijital hizmet vergisinin, Dijital Hizmet Vergisi Kanunu'nun md. 6/7'si uyarınca gelir ve kurumlar vergisi matrahından indirileceği bu nedenle bir eşitsizlik ortaya çıkarmayacağı iddia edilebilir. Ancak hiç kuşku yok ki matrahtan yapılacak indirim, ödenmiş olan dijital hizmet vergisi miktar ı uyarınca mükellefe bir kazanç sağlamayacaktır (Rençber, 2020: 32).

- Dijital hizmet vergisiyle ilgili vergiyi doğuran olayın, mükellefin, vergi matrahının ve vergi borcunun belirlenmesi ile verginin tahsili alanında yaşanacak güçlüklerin vergi sorumlusu yoluyla aşılması öngörülmektedir. Burada özellikle banka ve diğer kredi kuruluşları önemli bir role sahip olacaklardır. Ödemenin tamamen yurt dışı araçları kullanılarak yapııması (örneğin, yabancı kredi kartının ya da yabancı banka hesaplarının kullanılması) halinde burada bazı sıkıntılar ortaya çıkacağı açıktır. Bu tür durumlar için gecikmeden hukuka uygun önlemler planlanması gerekmektedir (Yavaşlar, 2020: 20)

- Dijital hizmet vergisinin, haberleşme hizmeti sunmaya yönelik olan sosyal medya platformlarını da mükellef kılması nedeniyle, haber alma ve verme özgürlüğü açışından da incelenmesi gerekmektedir. Verilecek olan olası erişimin engellenmesi kararları içerik itibariyle ifade özgürlüğünü ihlal etmesi nedeniyle de sorunludur (Rençber, 2020: 33).

- Ülke uygulamalarına bakıldığında $\% 7,5^{\prime}$ lük oran efektif vergi yükü açısından oldukça yüksek kalmaktadır.

- Hasılat esaslı bir vergi yükümlülüğünün Çifte Vergilendirmeyi Önleme Anlaşmalarının konusuna girebileceği şeklinde de literatürde yorumlar bulunmaktadır (Rençber, 2020: 34). 
- Dijital hizmet vergisi ayrı-bağımsız (müstakil) bir kanunla düzenlenmemektedir. İlgili düzenleme torba kanun içinde yer almaktadır. Dolayısıyla dijital hizmet vergisine ilişkin istisna ve muafiyetlerin söz konusu Kanun'a hüküm eklemek veya değişiklik yapmak suretiyle düzenleneceği hükmü anlamlı görülmemektedir (Saraçoğlu ve Kahraman, 2020: 14).

- Dijital hizmet vergisinin, OECD’nin dijital ekonominin vergilenmesi hakkında uluslararası bir "uzlaşma" ile kalıcı bir çözüm geliştirmesi durumunda, kaldırılacağına ilişkin Kanun'da bir hüküm bulunmaması diğer bir problemli alandır (Ülkü, 2020: 122).

\subsection{Diğer Yasal Düzenlemeler}

VUK' un “vergi kesenlerin sorumluluğunu” düzenleyen 11 inci maddesine yeni bir fıkra eklenmiş ve daha sonra buna paralel GVK'nun 94 üncü maddesinde, KVK'nın 15 ve 30 uncu maddelerinde düzenlemeler yapılmıştır. Yapılan bu düzenlemelerden sonra, 476 sayılı Cumhurbaşkanı Kararı uyarınca, internet ortamında verilen reklam hizmetleri vergi kesintisi kapsamına alınmış olup bu hizmetlere ilişkin olarak hizmeti verenlere veya internet ortamında reklam hizmeti verilmesine aracılık edenlere yapılan ödemelerden, ödeme yapılan kişilerin mükellef olup olmamasına bakılmaksızın 1/1/2019 tarihinden itibaren vergi kesintisi yapılacağı kararlaştırılmıştır. Ancak bu uygulama ÇVÖA hükümlerine aykırılık teşkil ettiği şeklinde değerlendirilerek mükellef kurumlar nezdinde dava konusu yapılmaktadır.

Yine 3065 sayılı Katma Değer Vergisi Kanununun da düzenleme yapmış ve Türkiye'de ikametgahı, işyeri, kanuni merkezi ve iş mer kezi bulunmayanlar tarafından katma değer vergisi mükellefi olmayan gerçek kişilere elektronik ortamda sunulan hizmetlere ilişkin KDV'nin, bu hizmeti sunanlar tarafından beyan edilip ödenmesi sağlanmıştır (3 No'lu KDV beyannamesi).

Ayrıca Türkiye düşük değerli mallar için gümrük muafiyet sınırını sıfırlamıştır. Böylece bunlardan da değerine bağlı sabit bir oranda gümrük vergisi alınması sağlanmıştır (Oktay, 2020: 115).

\section{DIJITAL EKONOMININ VERGILENDIRILMESINE YÖNELIKSORUNLAR}

Mevcut uluslararası vergilendirme kuralları; karın, fiziksel varlığın (sabit işyerinin) bulunduğu yerde vergilendirilmesi esa sına dayanmaktadır (Berk, 2018). Dijital dönüşüm ile birlikte fiziki varlığın artık önemini kaybetmesi bu faaliyetlerin vergilendirilmesinde temel sorun olarak karşımıza çıkmaktadır. Bir başka ifade ile dijitalleşme, işletmelerin yerel düzeyde herhangi bir hukuki veya fiziksel varlığa ihtiyaç duymadan pazardaki paylarını artırmalarını ve elde ettikleri karıvergi dışı bırakmalarını mümkün kılmaktadır (European Parliament, 2016: 23).

Dijital ekonominin vergilendirilmesi ile ilgili sorunları aşağıdaki şekilde özetleyebiliriz (Yılmaz ve Değer, 2018):

- Mükellefiyetin tespiti ve belirlenmesi,

- Elde edilen gelirin niteliğinin/türünün belirlenmesi,

- Gelirin elde edildiği yerin belirlenmesi,

- Elde edilen gelirin tutarının ve vergiye tabi gelirin (vergi matrahının) belirlenmesi (ilişkili işlemler bulunması halinde transfer fiyatlandırması düzenlemelerine göre emsallere uygunluk ilkesi çerçevesinde belirlenmesi)

- Uygulanacak vergileme rejiminin belirlenmesi (stopaj, doğrudan vergileme v.b.),

- Harcama üzerinden alınan vergilerin (dolaylı vergiler) (KDV, ÖTV gibi) nasıl uygulanacağı?

Yine dijital süreçlerin gizlilik ve sanallaştırma özelliklerine sahip olması nedeniyle, vergi mükelleflerinin gerçek kimliğin in belirlenmesi ulusal vergi otoriteleri açısından bir güçlüktür (Budak, 2017: 298).

Dijital ekonominin çeşitliliği de tek bir vergilendirme rejiminin uygulanmasını zorlaştırmaktadır (Tax Journal, 2018:8).

Dijital ekonomi; esas itibarıyla, BEPS'i (Base Erosion and Profit Shifting-Matrah Aşındırması ve Kar Aktarımı) kolaylaştırmakta (Birinci, 2019: 511-512) ve yukarıda sıralanmaya çalışıldığı üzere doğrudan ve dolaylı vergiler açısından ülkelerin bu alanda elde edilebileceği vergi gelirlerinden maalesef mahrum kalmasına neden olmaktadır.

Doğrudan vergiler açısından sorunları temel anlamda üçe ayırabiliriz (Artar, 2019: 245): Bunlar,

- $\quad$ Nexus (rabıta, bağ),

- Veri (data),

- $\quad$ Gelirin niteliğidir (karakterizasyon)

İrtibat bürosu ya da daimi işyeri olarak da ifade edilen "nexus", dijital dönüşüm ile birlikte fiziki varlığın artık önemini kaybetmesi gerçeğinden hareketle işyerinin veya irtibat bürosunun yeniden tanımlanması ve gelirin ait olduğu işyerinin tespiti ihtiyacından doğmuştur (Artar, 2019: 245). Ayrıca, "veri"lerin dijital ekonomideki artan ve genişleyen rolü; verinin değerinin tespit edilmesi başta olmak üzere, bunların kullanılması, depolanması ve toplanmasına ilişkin sorunların yanı sıra bu verilere ilişkin gelir paylaşımının nasıl yapılacağı problemini de beraberinde getirmiştir (Artar, 2019: 245). Son olarak, özellikle bulut bilişim alanında yaşanan gelişmeler ile birlikte söz konusu hizmetlere ilişkin gelir türünün belirlenmesinde birtakım sorunlar ortaya çıkmıştır (ticari, serbest meslek, gayri maddi hak vb.) (Artar, 2019: 245-246).

Dolaylı vergiler açısından asıl sorun katma değer vergisi (KDV) açısından yaşanmaktadır. Bu alandaki sorunların dijital ve fiziksel ürünlerin ayrımından kaynaklandığını söyleyebiliriz (Artar, 2019: 78). Çünkü fiziki ürünler gümrükten geçtiği için vergilendirme açısından bir sorunla karşılaşılmamaktadır (Kara ve Öz, 2016, s. 34-35). Dijital ürünlerde ise işlemler elektronik ortamda gerçekleştiğinden ülkelerin vergi otoriteleri tarafından bunların tespiti neredeyse imkansızlaşmakta ve vergilendirmeye yetkili olan ülkenin belirlenmesinde sorunla $r$ ortaya çıkmaktadır (Kara ve Öz, 2016: 34-35). Katma değer vergisi açısından diğer bir sorun dijital aracıların varlığı sebebiyle çifte vergilendirme riskinin söz 
konusu olabilmesidir (Artar, 2019: 246). Çünkü, dijital işlemlerin gerçekleştiği bazı durumlarda tek bir tüketicinin aynı hizmet için birden fazla katma değer vergisi ödeme ihtimali söz konusu olabilmektedir (Artar, 2019: 246).

Dijital ekonominin vergilendirilmesinde BSMV, gümrük vergisi ve damga vergisiaçısından da birtakım sorunlar söz konusu olabilmektedir. Örneğin dijital mal ve hizmetlerin gümrükten geçme zorunluluğu olmadığından, ya vergiden muaf edilmesi ya da işlemin muhataplarının sorumlu tutulması gerekmektedir (Kara ve Öz, 2016: 35). Dijital ortamda gerçekleştirilen işlemlerle ilgili olarak sözleşmelerin elektronik ortamda düzenlendiği görülmektedir. Elektronik ortamda gerçekleştirilen sözleşmelerin hukuki açıdan kabul edilmesi durumunda, ortada düzenlenen ve imzalanan bir kağıt bulunmadığından yapılan işlem, damga vergisi kapsamına giren bir işlem olarak nitelendirilememektedir (Kayıhan ve Yıldız, 2004: 164). Bankacılık faaliyetlerinin vergi cenneti olarak kabul edilen ülkeler üzerinden yürütülmesi ülkelerin vergi idarelerinin BSMV gelirlerinden mahrum kalmasına neden olmaktadır.

Dijital ekonominin vergilendirilmesi aşamasında karşılaşılan önemli sorunlardan birisinin de "denetim" olduğunu söyleyebiliriz (Yüce ve Akbulut, 2018: 113). Çünkü uzaktan satıştan doğan gelirler mevcut klasik denetim teknik ve yaklaşımıyla istenilen ve beklenilen düzeyde denetlenememektedir. Ayrıca, dijital ekonomide tarafların (alıcı ve satııı) çoğu kez farklı ülkelerde mukim olmaları dikkate alındığında yargılama yetkisi konusunda da sıkıntılar yaşanabilmektedir (Yüce ve Akbulut, 2018: 113).

\section{SONUÇ VE DEĞERLENDIRMELER}

Bilgi teknolojilerinin gelişmesine bağlı olarak dijital ortamda gerçekleştirilen ekonomik faaliyetler uluslararası piyasada önemli bir hacme ulaşmıştır. Bu çerçevede ticari ve ekonomik faaliyetler artık internet ortamında da (sanal) gerçekleşmektedir. Ancak bu yeni iş modeli beraberinde bazı problemleri de beraberinde getirmektedir. Bu problemlerin başında mevcut vergisel düzenlemelerin dijital sür eçleri kavramadaki yetersizliği gelmektedir. Bu nedenle dijital ekonominin vergilendirilmesinde kar şılaşılan problemlerin çözümüne yönelik gerek ulusal gerekse uluslararası düzeyde önemli ve etkin çalışmalar yapılmaktadır.

OECD matrah aşındırma ve kar aktarımı ile ilgili BEPS eylem planını yayımlamıştır. 1. Plan kapsamını dijital ekonominin yarattı̆̆ vergisel sorunların tespiti oluşturmaktadır. Bu çerçevede ara rapor Nisan 2018' de yayımlanmıştır ve nihai raporun 2020' de bitirilmesi beklenmektedir. Konuyla ilgili $A B$ düzeyinde de çalışmalar yürütülmektedir. Bunun yanı sıra ülkeler yürürlüğe koy duğu tek taraflı regülasyonlar ile dijital ekonominin vergilendirilmesine yönelik aksiyonlar almıştır. Türkiye' de dijital ekonominin kayıt altına alınmasına yönelik politikalar geliştirmiş ve Mart 2020'den itibaren uygulanmak için dijital hizmet vergisi ihdas etmiştir. Uygulanan dijital işlem vergisi, hasılat üzerinden nispi oran uygulanmak suretiyle hesaplanmaktadır. Ancak söz konusu vergisi beraberinde birçok tartışmayı da beraberinde getirmiştir. Bu eleştiriler literatürde özellikle "mali güce göre vergilendirme ilkesi”, "verginin belirliliği ilkesi", "eşitlik ilkesi", "haber alma ve verme özgürlüğü", "verginin oranı" ve "verginin uygulanabilirliği" başlıkları çerçevesinde yapılmaktadır. Yine dijital hizmetlerin vergilendirilmesine yönelik doğrudan ve dolaylı vergi düzenlemeleri yapılmıştır. Özellikçe tevkifat uygulaması ÇVÖA anlaşmalarının ticari kazanç hükümlerine aykırılk teşkil etmesi nedeniyle mükellefler nezdinde dava konusu yapılmaktadır.

Dijital ekonominin ülke sınırlarını aşan yönü dikkate alındığında ülkelerin bu tek yönlü vergisel uygulamalarının mevcut sorunun çözümünde yetersiz kaldığı görülmektedir. Dolayısıyla; ülkelerin haklarını gözeten, vergi planlaması yapmayı ve vergiden kaçınmayı önle yen yöntemlerin geliştirilmesi için OECD düzeyinde adil, çok tarafı bir uluslararası çözüm bulunması gerekliliği ön plana çıkmıştır. Birbaşka ifade ile bu yönde atılacak adımların şirketler arasında eşitliğin korunması ve sağlanması adına uluslararası düzeyde ele alınması ve gerekli konsensüsün sağlanması önem arz etmektedir.

\section{KAYNAKLAR}

6563 Sayılı Elektronik Ticaretin Düzenlenmesi Hakkında Kanun. https://www.mevzuat.gov.tr/MevzuatMetin/1.5.6563.pdf

7194 Sayılı Dijital Hizmet Vergisi ile Bazı Kanunlarda ve 375 Sayılı Kanun Hükmünde Kararnamede Değişiklik Yapılması Hakkında Kanun. https://www.resmigazete.gov.tr/eskiler/2019/12/20191207-1.htm

Akyazı, H., Kalça, A. (2003). Yeni Ekonomi ve İktisat Bilimi. Liberal Düşünce Dergisi, (29): 221-242.

Artar, Y. (2019). Dijital Ekonomide Vergileme, Finansal Raporlama ve Denetime illişkin Sorunlar: Türkiye Açısından Çözüm Önerileri. Yayımlanmamış Doktora Tezi. İstanbul Ticaret Üniversitesi. Muhasebe ve Denetim Doktora Programı.

Aslan, Ö. (2009). Yeni Ekonomi: Özellikleri ve Endüstrileri. https://dergipark.org.tr/tr/download/article-file/9106

Ber, H. (2018). Dijital Ekonominin Vergilendirilmesi Sorunsalına Genel Bir Bakış. https://vergialgi.net/dijital-ekonominin-vergilendirilmesisorunsalina-genel-bir-bakis

Birinci, N. (2019). Dijitalleşmenin Vergi Matrahına Etkisi ve Tek Taraflı Önlemler. Maliye Dergisi. 176: 5050.527.

Boccia, F. (2016). Introduction: The Digital Economy and Fiscal Policy in the Age of E-Commerce. The Challenge of the Digital Economy: Pagrave Macmillan.

Budak, T. (2017). The Transformation of International Tax Regime: Digital Economy. Inönü Üniversitesi Hukuk Fakültesi Dergisi. 8(2): 297-330. 
Dijital Hizmet Vergisi Uygulama Genel Tebliği. https://www.resmigazete.gov.tr/eskiler/2020/03/20200320-4.htmEuropean Parliament (2016). Tax Challenges in the Digital Economy. Brussel.

Kara, M. C., Öz, E. (2016). Dijital Vergilendirmeye Küresel Bir Bakış. Vergi Dünyası Dergisi. 424: 30-37.

Kayıhan, Ş., Yıldız, H. (2004). Elektronik Ticaretin Hukuki ve Vergi Boyutu. Ankara: Seçkin Yayınclık.

Mastar Özcan, P. (2016). Dijital Ekonominin Vergilendirilmesinde Karşılaşılan Sorunlar: BEPS 1 No'lu Eylem Planı Kapsamında Bir Değerlendirme. Electronic Journal of Vocational Colleges. 6/2: 73-82.

OECD. (2015). Addressing the Tax Challenges of the Digital Economy, Action 1-2015 Final Report. https://read.oecdilibrary.org/taxation/addressing-the-tax-challenges-of-the-digital-economy-action-1-2015-final-report 9789264241046-en\#page1

Oktay, C. (2020). Dijital Ekonominin Boyutu, Vergilendirilmesine Yönelik OECD Çalışmaları, Öneriler, Örnek Ülke Uygulamaları ve Türkiye'de Yapılan Düzenlemeler ve Dijital Hizmet Vergisi. Vergi Sorunları Dergisi. 376: 95-116.

Rençber, A. (2020). Dijital Hizmet Vergisi İlk İzlenimler, Sorun ve Sorunsallar. Vergi Sorunları Dergisi. 376: 27-35.

Saraçoğlu, F., Kahraman, B. (2020). Dijital Hizmet Vergisi Üzerine Değerlendirmeler. Vergi Sorunları Dergisi. 376: 9-17.

Tax Journal. (2018). Taxation of the Digital Economy: Unilateral Measures. Insight and Analysis for the Business Tax Community, 1389: 7-13. Ülkü, Y. E. (2020). Türkiye’deki “Dijital Hizmet Vergisi Önerisinin İncelenmesi. Vergi Sorunları Dergisi. 377: 106-125.

Yavaşlar, B. F. (2020). Dijital Hizmet Vergisi. Vergi Sorunları Dergisi. 377: 9-20.

Yüce, M., Akbulut, N. (2018). BEPS Eylemi Kapsamında Dijital Ekonominin Vergilendirilmesine illişkin Alınan Önlemler. Akademik Bakış Dergisi. 68: 105-123.

Yıldız, B., Günay, H. (2018). Türk VergiHukukuEkseninde Dijital Ekonomiye Genel Bir Bakış. III. Uluslararası Meslekive Teknik Bilimler Kongresi, Kongre Tam Metin Kitabı. Cilt 6: 4004-4012.

Yılmaz, G.H., Değer, A.A. (2018). The Permanent Establishment Paradox in Digital Economic Activities and Underlying Turkish Tax Implications. https://www.verginet.net/dtt/18/DijitallktisadiFaaliyetlerdelsyeriParadoksuveVergiselBoyutu. aspx?lng=1 